\title{
Gender Differences in Risk Behaviours: Does Sexual Maturation Matter?
}

\section{Abstract}

Background: Menarche is a milestone of entering puberty, representing an indicator of sexual maturity and revealing normal physical, biological, psychological, and emotional development. This study aimed to compare pre-menarche girls, same age post-menarche girls, and boys according to risk behaviours.

Methods: Participants ( $n=2608$ ) completed a comprehensive survey regarding headache, irritability, feeling nervous, tobacco use, drinking beer, physical fighting, diet, and perception of health.

Results: The prevalence of having headaches $(p<0.001)$, being irritable or having a bad temper $(p<0.001)$, feeling nervous $(p<0.001)$, being on a diet $(p<0.001)$ was significantly higher among post-menarche girls than boys and pre-menarche girls. Post-menarche girls had a poorer perception of health $(p<0.001)$. After adjusted data for socioeconomic status and BMI, frequency of having headaches, bad temper and feeling nervous was higher for post-menarche girls.

Conclusions: Specific school-based intervention is required so that the perception of well-being and social participation can be maintained during after menarche.

Keywords

Adolescence, gender differences, health behaviours, attitudes
Adilson Marques 1,2,3, Cátia Branquinho 1,2, Margarida Gaspar de Matos ${ }^{1,2}$

1 Projeto Aventura Social, Universidade de Lisboa, Lisboa, Portugal.

2 ISAMB - Instituto de Saúde Ambiental, Faculdade de Medicina, Universidade de Lisboa, Lisboa, Portugal.

3 Centro Interdisciplinar de Estudo da Performance Humana, Faculdade de Motricidade Humana, Universidade de Lisboa, Cruz Quebrada, Portugal

\section{Contact information:}

\section{Adilson Marques.}

Tel: (351) 214149100

Address: Faculda de Motricida de Humana, Estrada da Costa, 1499-002 Cruz Quebrada, Portugal.

\section{”' amarques@fmh.ulisboa.pt}

\section{Introduction}

Adolescence is a stage of life characterized by rapid growth and development. In girls, menarche is considered the milestone of entering puberty, representing an indicator of sexual maturity and revealing normal physical, biological, psychological, and emotional development 
[1-3]. Although there is variability in the menarche age, European and North-American studies pointed out a menarche age of between twelve and thirteen years [4-6]. In boys, it is difficult to determine at what age this stage begins, because there is no event that culminates this life phase. Spermarch, although rarely used in research to study the onset of puberty, is the limit between childhood and adolescence in boys [7].

Menstruation has an important role in emotional regulation and is associated with many physical symptoms during the menstrual cycle in girls [8]. Its beginning is related to a host of factors: physical, socioeconomic, environmental, ethnicity, body mass index (BMI), geography, and eating habits $[3,9]$.

When analysing subjective health complaints (e.g. headaches, abdominal and muscle pain, sadness, irritability, nervousness, sleeping difficulty, and dizziness) between girls and boys, it appears that girls report a higher level of symptoms [10, 11]. Girls also present a lower health perception, in terms of selfimage and incidence of physical and mental symptoms, when compared to boys [8]

In the study of risk behaviours associated with adolescence, it appears that in the post-pubertal period, girls have a higher consumption of alcohol than boys, are more likely to use inhalants and stimulants, and tend to start smoking before the opposite sex; while boys present a higher level of risk behaviours in other areas such as violent behaviours, engaging in fights, and accidents [12, 13]. Early menarche constitutes a factor that enhances the predisposition to alcohol abuse and also the beginning of sexual activity at a premature age (before aged 15) [14], and in addiction to a higher rate of alcohol consumption, as well as an increased use of cigarettes and marijuana [15, 16]. In boys, early puberty is associated with engaging in fights, and aggressive responses in emotional situations during early adolescence [17].

Since adolescence is a period of physical and psychological maturation, but also associated with different levels of risk behaviours in girls and boys, the aim of the present study was to use data from a large population study in order to compare three groups: pre-menarche girls, same age post-menarche girls, and boys. The study of gendered risky behaviours, and its association with pubertal status in girls, is essential in order to better adjust health preventive and promotional interventions to different stages of development of young people, while taking into consideration gendered differences.

\section{Methods}

\section{Participants}

This study is based on data from the Health Behaviour in School-Aged Children (HBSC) Portuguese survey [18]. The HBSC is a school-based survey of adolescents' health behaviours, carried out every 4 years. HBSC Portugal is one of 43 countries and regions across Europe and North America that integrate the HBSC Network. Data is collected using an international standardized methodological protocol [19], to gain new vision into young people's health and well-being, to understand the social and psychological determinants of health, and to incorporate policies to improve young people's lives. For the present study the sample consisted of 2608 children aged 10-13 years, attending grades 6 and 8, from the HBSC 2010 waves. Children aged 10-13 were selected because there was an intention to have three groups: boys, pre-menarche girls and postmenarche girls.

\section{Measures}

\section{Gender, age, socioeconomic status, menarche age, weight, and height.}

Socio-demographic variables were: gender, age, and socioeconomic status (SES). Gender and age were self-reported. The Graffar scale, emphasizing parents' occupation, was used to identify the SES. 
To determine age at menarche, girls were asked if they had had their first menstruation (status quo method). Weight and height were self-reported. BMI was then calculated based on mass (kilograms) divided by height (square metres). Adolescents' BMI class and BMI z-score were determined based on International Obesity Taskforce criteria [20], with overweight and obesity defined as an adult BMI equivalent $\geq 25$ and obesity $\geq 30$. Overweight and obese were defined simply as overweight/obese.

\section{Headache, irritability or bad temper, and feeling nervous}

The frequency of headaches, being irritable, and feeling nervous was listed as a single multipart question: "In the last 6 months, how often have you...?" For each question children were required to specify the frequency on a five point scale: (1) rarely or never, (2) about every month, (3) about every week, (4) more than once a week, (5) about every day.

\section{Tobacco use}

Tobacco use status was defined on the basis of the question, "How often do you smoke tobacco at present". Possible responses included: (1) do not smoke, (2) less than once a week, (3) once a week, (4) every day.

\section{Drinking beer}

The frequency of drinking beer was assessed by asking, "How often do you drink beer?". The following multiple-choice answers were included: (1) never, (2) rarely, (3) every month, (4) every week, (5) every day.

\section{Physical fighting}

Children were asked how many times during the last 12 months they had been involved in a physical fight. Responses were given in a 5-point scale (1) none, (2) one time, (3) two times, (4) three times, (5) four times or more.

\section{Diet}

Children were asked if they were currently trying to lose weight or if they needed to lose weight. Answers were included (1) no, I am pleased with my weight, (2) no, but I should have to lose weight, (3) no, I need to put on some weight, (4) yes. To simplify, the responses were dichotomized as yes or no.

\section{Perception of health}

Perception of health was assessed through the question, "How would you rate your health?" Answers were given, through selection, on a 4-point scale: (1) poor, (2) fair, (3) good, (4) excellent.

\section{Procedure}

The survey was based on a self-administered standardized questionnaire administrated by teachers, or members of the research group, in the classroom in public schools randomly selected from Portuguese administrative regions. After completion, the children were asked to put the questionnaire in an envelope, seal it, and hand it to the teacher or to a member of the research group. The study was anonymous, making it impossible to conduct an individual non-response analysis. Research was approved by the Ethical Committee of Porto Medical School, and was in accordance with the rules of the National Data Protection System. All school administrators gave their consent; legal guardians gave written informed consent. This study followed all scientific and ethics recommendations for research on humans. The study was also authorized by the Ministry of Education. Children participated on an anonymous and voluntary basis. A detailed chapter regarding methods is available [18].

\section{Data analysis}

Descriptive statistics were calculated (means, standard deviation and percentages) for the sample according to gender and girls menarche status. 


\section{INTERNATIONAL ARCHIVES OF MEDICINE \\ Section: Global Health \& Health Policy \\ ISSN: 1755-7682}

Chi-square and Kruskal-Wallis were used to assess differences among boys, girls pre-menarche, and girls post-menarche in relation to headache, irritability temper, feeling nervous, tobacco use, drinking beer, physical fighting, being on a diet, and perception of health. To identify which group was different from others, multiple comparisons of rank cases were performed through the LSD Fisher test. Because most risk behaviours variables were ordinal, they were treated as continuous variables. Thus, they were tested for normality. Because these variables did not have normally distributed residuals they were therefore log-transformed for analysis. For the comparison between boys, girls pre-menarche, and girls post-menarche (according risk behaviours) ANCOVA was used; age, BMI and SES were used as covariates. Statistical analyses were performed using IBM SPSS Statistics 22.0. The level of significance was set at 0.05 .

\section{Results}

Participants' characteristics are presented in table 1.

The prevalence of having headaches $(x 2 \mathrm{KW}(2)$ $=69.582, p<0.001)$, being irritable or having a bad temper $(\chi 2 \mathrm{KW}(2)=43.803, p<0.001)$, feeling nervous $(x 2 \mathrm{KW}(2)=59.571, p<0.001)$, being on a diet $(\chi 2(2)=22.456, \quad p<0.001)$ was significantly higher among post-menarche girls than boys and pre-menarche girls. Conversely, post-menarche girls had
Table 1. Characteristics of the participants.

\begin{tabular}{|l|c|c|}
\hline \multicolumn{1}{|l|}{} & N & $\%$ \\
\hline Gender & & \\
\hline Boys & 1284 & 49.2 \\
\hline Pre-menarche girls & 583 & 22.4 \\
\hline Post-menarche girls & 741 & 28,4 \\
\hline Age & & \\
\hline 10-11 years & 1113 & 42.6 \\
\hline 12-13 years & 1495 & 57.4 \\
\hline SES & & \\
\hline Low & 276 & 10.6 \\
\hline Middle/low & 1047 & 40.1 \\
\hline Middle & 397 & 15.2 \\
\hline Middle/high & 237 & 9.1 \\
\hline High & 282 & 14.6 \\
\hline BMl & & \\
\hline Normal weight & 1884 & 75.9 \\
\hline Overweight/obese & 597 & 24.1 \\
\hline Abbreviation: SES, socioeconomic status & \\
\hline
\end{tabular}

a poorer perception of health $(\chi 2 \mathrm{KW}(2)=51.623$, $p<0.001)$ than boys and pre-menarche girls. Premenarche girls had a lower rate of tobacco use $(\chi 2 \mathrm{KW}(2)=27.259, \mathrm{p}<0.001)$ and beer consumption $(\chi 2 \mathrm{KW}(2)=68.031, p<0.001)$. On the other hand, the prevalence of physical fighting was significantly higher among boys than girls $(\chi 2 \mathrm{KW}(2)=307.570$, $\mathrm{p}<0.001)$.

Table 2. Comparison among boys, pre-menarche girls and post-menarche girls, according headache, risk behaviours, and perception of health.

\begin{tabular}{|l|c|c|c|}
\hline & Boys & Pre-menarche girls & Post-menarche girls \\
\hline & $\mathrm{N}=1284$ & $\mathrm{~N}=583$ & $\mathrm{~N}=741$ \\
\hline & $\%$ & $\%$ & $\%$ \\
\hline Headache $^{\mathrm{N}}$ & & & \\
\hline Rarely or never & 78.3 & 75.9 & 61.4 \\
\hline About every month & 9.3 & 9.5 & 14.7 \\
\hline About every week & 3.8 & 3.3 & 7.9 \\
\hline More than once a week & 5.0 & 9.3 & 11.8 \\
\hline About every day & 3.5 & 2.1 & 4.2 \\
\hline
\end{tabular}




\begin{tabular}{|c|c|c|c|c|}
\hline \multicolumn{5}{|l|}{ Irritability or bad tempera } \\
\hline Rarely or never & 63.6 & 70.1 & 52.5 & \multirow{5}{*}{$<0.001^{1}$} \\
\hline About every month & 18.6 & 14.0 & 22.6 & \\
\hline About every week & 6.8 & 6.0 & 8.7 & \\
\hline More than once a week & 7.2 & 6.9 & 11.7 & \\
\hline About every day & 3.8 & 2.9 & 4.4 & \\
\hline \multicolumn{5}{|l|}{ Feeling nervous ${ }^{a}$} \\
\hline Rarely or never & 59.9 & 60.4 & 43.9 & \multirow{5}{*}{$<0.001^{1}$} \\
\hline About every month & 19.0 & 18.5 & 22.5 & \\
\hline About every week & 8.2 & 6.1 & 12.4 & \\
\hline More than once a week & 8.2 & 9.2 & 14.3 & \\
\hline About every day & 4.7 & 5.9 & 6.9 & \\
\hline \multicolumn{5}{|l|}{ Tobacco use $\mathrm{a}^{\mathrm{a}}$} \\
\hline Do not & 95.5 & 98.6 & 92.4 & \multirow{4}{*}{$<0.001^{2}$} \\
\hline Less than once a week & 2.6 & 0.5 & 4.8 & \\
\hline Once a week & 0.7 & 0.7 & 1.8 & \\
\hline Every week & 1.1 & 0.2 & 1.0 & \\
\hline \multicolumn{5}{|l|}{ Drinking beera } \\
\hline Never & 76.9 & 92.6 & 78.4 & \multirow{5}{*}{$<0.001^{2}$} \\
\hline Rarely & 19.4 & 7.3 & 19.0 & \\
\hline Every month & 2.7 & 0.0 & 2.2 & \\
\hline Every week & 0.9 & 0.2 & 0.4 & \\
\hline Every day & 0.1 & 0.0 & 0.0 & \\
\hline \multicolumn{5}{|l|}{ Physical fighting } \\
\hline None & 53.7 & 87.7 & 82.4 & \multirow{5}{*}{$<0.001^{3}$} \\
\hline 1 time & 20.3 & 8.8 & 9.0 & \\
\hline 2 times & 9.2 & 1.4 & 4.6 & \\
\hline 3 times & 5.4 & 0.9 & 1.8 & \\
\hline 4 or more times & 11.5 & 1.2 & 2.2 & \\
\hline \multicolumn{5}{|l|}{$\operatorname{Diet}^{a}$} \\
\hline No & 92.6 & 93.2 & 87.0 & \multirow{2}{*}{$<0.001^{1}$} \\
\hline Yes & 7.4 & 6.8 & 13.0 & \\
\hline \multicolumn{5}{|l|}{ Perception of health ${ }^{a}$} \\
\hline Poor & 0.5 & 0.2 & 0.3 & \multirow{4}{*}{$<0.001^{1}$} \\
\hline Fair & 8.7 & 9.7 & 14.4 & \\
\hline Good & 48.7 & 49.0 & 58.0 & \\
\hline Excellent & 42.2 & 41.1 & 27.2 & \\
\hline \multicolumn{3}{|l|}{ a Tested by Chi-square } & \multicolumn{2}{|l|}{ b Tested by Kruskall-Wallis } \\
\hline \multicolumn{5}{|c|}{${ }^{1}$ Girls are significantly different from boys and girls pre-menarche. } \\
\hline \multicolumn{5}{|c|}{$\begin{array}{l}2 \text { Girls pre-menarche are significantly different from boys and girls. } \\
3 \text { Boys are significantly different from girls pre-menarche and girls p }\end{array}$} \\
\hline${ }^{3}$ Boys are significantly dif & $m$ girls & e and $g$ & rche & \\
\hline
\end{tabular}


The comparison analysis among boys, pre-menarche girls and post-menarche girls adjusted for age, BMI and SES is presented in table 3. The frequency of having headaches in the last 6 months was higher for post-menarche girls, followed by pre-menarche girls and then boys. The results were significantly different among each other's group $(F(2)=27.985, p<0.001)$. Although the frequency of physical fighting was much higher among boys than among both groups of girls, all groups were also significantly different from one another $(F(2)=148.227, p<0.001)$. Regarding irritability or bad temper $(F(2)=12.600, p<0.001)$ and feeling nervous $(F(2)=18.982, p<0.001)$, post-menarche girls reported to have these feelings more often than boys and pre-menarche girls. Conversely, post-menarche girls had a significantly lower perception of health than boys and pre-menarche girls $(F(2)=21.479, p<0.001)$. Regarding beer drinking, boys and post-menarche girls have similar results, which were significantly higher than pre-menarche girls $(F(2)=10.214, p<0.001)$. Although tobacco uses were significantly different among boys, pre-menarche girls and post-menar- che girls in the previous analyses, when results were adjusted for covariates (age, BMI and SES), the differences were no longer significant.

\section{Discussion}

The results highlight that the prevalence of physical and psychological symptoms was significantly higher among post-menarche girls than boys and premenarche girls. Post-menarche girls also had a poorer perception of health than boys and pre-menarche girls, confirming gender differences presented in other studies $[10,11]$. The prevalence of physical fighting was significantly higher among boys than in girls, also confirming results from other studies [12].

The comparison analysis among boys, pre-menarche girls and post-menarche girls adjusted for age, BMI and SES confirmed that the frequency of having a headache in the last 6 months, reporting irritability, reporting bad temper or feeling nervous was higher in post-menarche girls; while post-menarche girls had a significantly lower perception of health than boys and pre-menarche girls. Diffe-

Table 3. Comparison analysis among boys, pre-menarche girls and post-menarche girls adjusted for age, BMI and SES.

\begin{tabular}{|c|c|c|c|c|}
\hline $\begin{array}{l}\text { Risk behaviours and perception } \\
\text { of health }\end{array}$ & Boys & Pre-menarche girls & $\begin{array}{l}\text { Post-menarche } \\
\text { Girls }\end{array}$ & p \\
\hline Headache & $0.22 \pm 0.46$ & $0.27 \pm 0.50$ & $0.42 \pm 0.57$ & $<0.001^{1}$ \\
\hline Irritability or bad temper & $0.34 \pm 0.51$ & $0.31 \pm 0.50$ & $0.48 \pm 0.56$ & $<0.001^{2}$ \\
\hline Feeling nervous & $0.40 \pm 0.54$ & $0.43 \pm 0.56$ & $0.60 \pm 0.59$ & $<0.001^{2}$ \\
\hline Tobacco use & $0.04 \pm 0.18$ & $0.02 \pm 0.12$ & $0.07 \pm 0.24$ & 0.080 \\
\hline Drinking beer & $0.17 \pm 0.33$ & $0.06 \pm 0.19$ & $0.17 \pm 0.32$ & $<0.001^{3}$ \\
\hline Physical fighting & $0.50 \pm 0.59$ & $0.10 \pm 0.30$ & $0.17 \pm 0.40$ & $<0.001^{1}$ \\
\hline Perception of health & $1.19 \pm 0.21$ & $1.17 \pm 0.21$ & $1.12 \pm 0.22$ & $<0.001^{2}$ \\
\hline \multicolumn{5}{|c|}{$\begin{array}{l}\text { Abbreviation: BMI, body mass index; SES, socioeconomic status. } \\
\text { Risk behaviours and perception of health were treaty as continuous variables. Because these variables did not have normally } \\
\text { distributed residuals they were therefore log-transformed for analysis. } \\
\text { Tested by ANCOVA. Age, BMI and SES were used as covariates. }\end{array}$} \\
\hline \multicolumn{5}{|c|}{${ }^{1}$ Boys, pre-menarche girls, and post-menarche girls were different from each other. } \\
\hline \multicolumn{5}{|c|}{2 Post-menarche girls are significantly different from boys and pre-menarche girls. } \\
\hline
\end{tabular}


rences in health and risky behaviour between boys and girls during adolescence have been repeatedly pointed out [21-23]; this study confirms previous results. The new highlight is that the present analysis strongly supports the assumption that gendered differences increase after girls reach puberty, and that post menarche girls seem to be at an increased risk of bad health, both psychological and physical, compared to both boys and to nonmenarche girls.

Some methodological limitations should also be mentioned. First, there was no information about the actual menarche dates of the girls. However, status quo method is considered to be reliable for obtaining menarche dates. Second, the cross-sectional design does not allow conclusions of causal relationships between menarche and physical activity and sedentary behaviours.

This finding calls for: 1) specific measures regarding health preventive and promotional interventions in schools, in the family, and in the community, and 2) trying to find a better approach for post-menarche girls to avoid a bad health perception which interferes with, and impairs, their sense of well-being and social participation. Measures can include: a) specific medical assistance to lower sickness perception and, in general, bad feelings related to menstruation days, and b) information about hormonal functioning and potential humour changes during menstruation days. Specific schoolbased educational intervention is required so that the perception of well-being and social participation can be maintained during menarche days, thereby decreasing its power as a risk factor regarding post menarche girls. Furthermore, early adolescence is a period where gender differences can be approached so that boys and girls can improve their means of coping with their emotional responses, increase their problem solving skills and increase their ability to search for adult help when necessary. Acquiring these skills will enable them to develop across adolescence $[18,24,25]$ and to enhance their behavioural repertoire, as well as their perception of well-being, while preventing risk behaviours and a poor perception of health.

\section{Acknowledgement}

The HBSC study in Portugal was funded by public funds: Ministry of Health and Ministry of Education and Science. The authors thank the children for their participation in the study, and the teachers for their assistance in helping collecting data. We also thank Professor Bruce Jones for revising the document.

\section{References}

1. Akther A, Islam R. A study on age at menarche of school going girls in Bangladesh. American Journal of Medicine and Medical Sciences. 2012; 2(2): 4-9. http://article.sapub. org/10.5923.j.ajmms.20120202.02.html

2. Biro FM, Galvez MP, Greenspan LC, Succop PA, Vangeepuram $\mathrm{N}$, Pinney SM, et al. Pubertal assessment method and baseline characteristics in a mixed longitudinal study of girls. Pediatrics. 2010; 126(3): e583-90. http://www.ncbi.nlm.nih. gov/pubmed/20696727

3. Kanotra S, Bangal V, Bhavthankar D. Menstrual pattern and problems among rural adolescent girls. IJBAR. 2013; 4(8). http:// www.ssjournals.com/index.php/ijbar/article/view/356

4. Talma $H$, Schonbeck $Y$, van Dommelen $P$, Bakker $B$, van Buuren S, Hirasing RA. Trends in menarcheal age between 1955 and 2009 in the Netherlands. PLoS One. 2013; 8(4): e60056. http:// www.ncbi.nlm.nih.gov/pubmed/23579990

5. Gohlke B, Woelfle J. Growth and puberty in German children: is there still a positive secular trend? Dtsch Arztebl Int. 2009; 106(23): 377-82. http://www.ncbi.nlm.nih.gov/ pubmed/19623318

6. Anderson SE, Must A. Interpreting the continued decline in the average age at menarche: results from two nationally representative surveys of U.S. girls studied 10 years apart. J Pediatr. 2005; 147(6): 753-60. http://www.ncbi.nlm.nih.gov/ pubmed/16356426

7. Ge X, Jin R, Natsuaki MN, Gibbons FX, Brody GH, Cutrona CE, et al. Pubertal maturation and early substance use risks among African American children. Psychol Addict Behav. 2006; 20(4): 404-14. http://www.ncbi.nlm.nih.gov/pubmed/17176175

8. Wu M, Zhou R, Huang Y. Effects of menstrual cycle and neuroticism on females' emotion regulation. Int J Psychophysiol. 2014; 94(3): 351-7. http://www.ncbi.nlm.nih. gov/pubmed/25312202 
9. Hillard PJ. Menstruation in adolescents: what do we know? And what do we do with the information? J Pediatr Adolesc Gynecol. 2014; 27(6): 309-19. http://www.ncbi.nlm.nih.gov/ pubmed/25438706

10. Haugland S, Wold B, Stevenson J, Aaroe LE, Woynarowska B. Subjective health complaints in adolescence. A crossnational comparison of prevalence and dimensionality. Eur J Public Health. 2001; 11(1): 4-10. http://www.ncbi.nlm.nih.gov/ pubmed/11276570

11. Wiklund $M$, Malmgren-Olsson EB, Ohman A, Bergstrom E, Fjellman-Wiklund A. Subjective health complaints in older adolescents are related to perceived stress, anxiety and gender -a cross-sectional school study in Northern Sweden. BMC Public Health. 2012; 12(993). http://www.ncbi.nlm.nih.gov/ pubmed/23158724

12. Mahalik JR, Levine Coley R, McPherran Lombardi C, Doyle Lynch A, Markowitz AJ, Jaffee SR. Changes in health risk behaviors for males and females from early adolescence through early adulthood. Health Psychol. 2013; 32(6): 685-94. http://www. ncbi.nlm.nih.gov/pubmed/23477574

13. Schinke SP, Fang L, Cole KC. Substance use among early adolescent girls: risk and protective factors. J Adolesc Health. 2008; 43(2): 191-4. http://www.ncbi.nlm.nih.gov/ pubmed/18639794

14. Gaudineau A, Ehlinger V, Vayssiere C, Jouret B, Arnaud C, Godeau $E$. Age at onset of menarche: Results from the French Health Behaviour in School-aged Children study. Gynecologie Obstetrique \& Fertilite. 2010; 38(6): 385-87. http://www. biomedcentral.com/1471-2458/10/175

15. Cance JD, Ennett ST, Morgan-Lopez AA, Foshee VA, Talley AE. Perceived pubertal timing and recent substance use among adolescents: a longitudinal perspective. Addiction. 2013; 108(10): 1845-54. http://www.ncbi.nlm.nih.gov/pubmed/23680010

16. Walls ML. Marijuana and alcohol use during early adolescence: Gender differences among American Indian/first nations youth. Journal of Drug Issues. 2008;3 8(4): 1139-60. https://www. ncjrs.gov/App/Publications/abstract.aspx?ID=248645

17. Downing J, Bellis MA. Early pubertal onset and its relationship with sexual risk taking, substance use and anti-social behaviour: a preliminary cross-sectional study. BMC Public Health. 2009; 9(446). http://www.ncbi.nlm.nih.gov/pubmed/19958543

18. Matos $M G$, Simões $C$, Tomé $G$, Camacho I, Ferreira $M$, Reis $M$, et al. A saúde dos adolescentes portugueses. Relatório do estudo HBSC 2010 [The health of Portuguese adolescents. Report of the 2010 HBSC study]. Cruz-Quebrada: Edições FMH; 2011.

19. Roberts C, Freeman J, Samdal O, Schnohr CW, de Looze ME, Nic Gabhainn S, et al. The Health Behaviour in School-aged Children (HBSC) study: methodological developments and current tensions. Int J Public Health. 2009; 54 Suppl 2(140-50. http://www.ncbi.nlm.nih.gov/pubmed/19639259
20. Cole TJ, Bellizzi MC, Flegal KM, Dietz WH. Establishing a standard definition for child overweight and obesity worldwide: international survey. BMJ. 2000; 320(7244): 1240-3. http:// www.ncbi.nlm.nih.gov/pubmed/10797032

21. Swain MS, Henschke N, Kamper SJ, Gobina I, Ottova-Jordan V, Maher CG. An international survey of pain in adolescents. BMC Public Health. 2014; 14 (447). http://www.ncbi.nlm.nih.gov/ pubmed/24885027

22. King S, Chambers CT, Huguet A, MacNevin RC, McGrath PJ, Parker $L$, et al. The epidemiology of chronic pain in children and adolescents revisited: a systematic review. Pain. 2011; 152(12): 2729-38. http://www.ncbi.nlm.nih.gov/pubmed/22078064

23. Abu-Arafeh I, Razak S, Sivaraman B, Graham C. Prevalence of headache and migraine in children and adolescents: a systematic review of population-based studies. Dev Med Child Neurol. 2010; 52(12): 1088-97. http://www.ncbi.nlm.nih.gov/ pubmed/20875042

24. Matos MG, Sampaio D. Jovens com saúde: diálogos com uma geração. Lisboa: Texto Editores, Lda; 2009.

25. Matos MG, Tomé G. [Social Adventure: promoting competences and social capital]. Lisboa: Placebo; 2012.

\section{Comment on this article:}
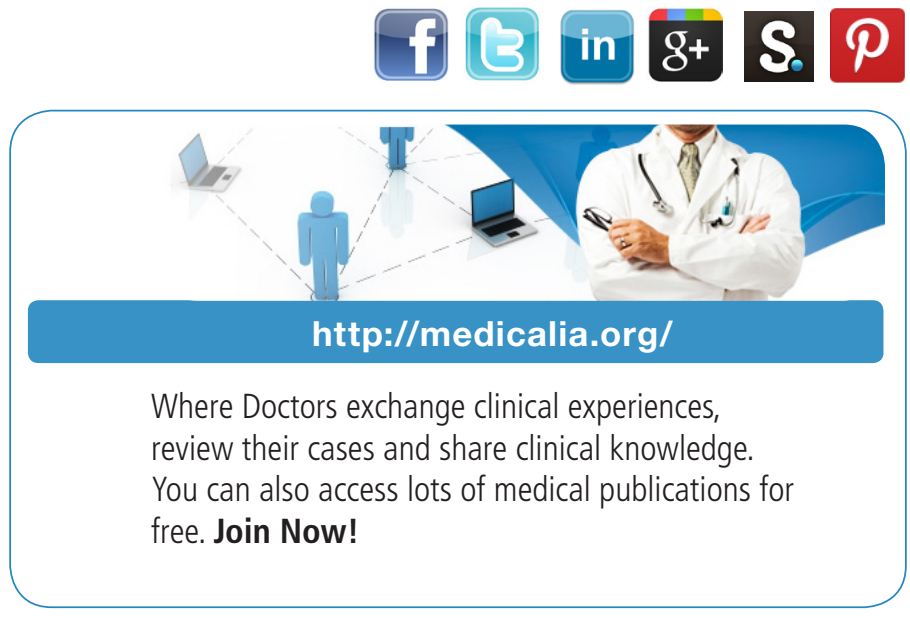

\section{Publish with iMedPub}

\section{http://www.imed.pub}

International Archives of Medicine is an open access journal publishing articles encompassing all aspects of medical science and clinical practice. IAM is considered a megajournal with independent sections on all areas of medicine. IAM is a really international journal with authors and board members from all around the world. The journal is widely indexed and classified Q1 in category Medicine. 